\title{
Research on Development of Liaoning Scientific Foreign Language Talents with View to Bourdieu's Theory
}

\author{
Huanhuan $\operatorname{Ren}^{1, a^{*}}$ and Chi Ma ${ }^{2, b}$ \\ ${ }^{1}$ Teaching and Research Institute of Foreign Languages, Bohai University, Jinzhou, China \\ ${ }^{2}$ Jinzhou Institute of Forestry Research, Jinzhou Forestry Bureau, Jinzhou, China \\ arenhuanhuan2014@163.com, ${ }^{\mathrm{b}}$ machi2014@tom.com
}

Keywords: Development; Liaoning; Scientific foreign language talents; Bourdieu's theory

\begin{abstract}
Scientific foreign language has drawn much attention of researchers and instructors in educational domain in China. With view to Bourdieu' theory, this paper aims at fostering scientific foreign language talents in Liaoning province of China. It's found that the insights into Liaoning scientific foreign language talents with view to Bourdieu' theory is profound and influential. Efforts should be made for learners to go for habitus to react to the world and for more capitals to make a change whist cultivating Liaoning scientific foreign language talents. It's suggested that pedagogical strategies on scientific foreign language be implemented through engaging learners in the process of updating learning habitus in learning, considering social context into learning, interacting with elements in economic field and getting access to all sorts of learning capitals, so as to ultimately develop linguistic competence among scientific foreign language talents.
\end{abstract}

\section{Introduction}

Foreign language learning has gain momentum for long in China, and scientific foreign language as one part of foreign language has also draw much attention of researchers and instructors in Chinese educational domain. This paper aims at fostering scientific foreign language talents in Liaoning province of China with view to Bourdieu' theory. In this thesis, we will introduce an overview of Bourdieu's theory of practice as our theoretical framework. Subsequently, we will apply elements of this theory to the context of Liaoning scientific foreign language teaching whereupon we will lead a critical discussion on the insights into the cultivation of Liaoning scientific foreign language talents. Finally, this paper presents strategies on developing Liaoning scientific foreign language talents with view to Bourdieu' theory. This paper is a summary of this research work, which hopefully provides a useful reference for future foreign language learning among scientific foreign language talents.

\section{Overview of Bourdieu's Theory}

Ideas about Bourdieu's Theory. At the center of Bourdieu's sociological work is logic of practice that emphasizes the importance of the body and practices within the social world. Three main elements, namely field, capital and habitus are comprised in Bourdieu's theory. What are field, capital and habitus? Fields are the various social and institutional arenas in which people express and reproduce their dispositions, and where they compete for the distribution of different kinds of capital [1]; capital is defined as sums of money or assets put to productive use; habitus are the dispositions the individual agent develops in response to the objective conditions they encounter. It's argued that habitus may be regarded as psychosomatic mind, capital as principal cause for distinction, and the field as relatively autonomous microcosm [2].The interplay of these elements leads to strategy or practice, i.e. unconscious behavior that is in conformity with our interests' aims at achieving our objectives by investing capital and fighting for capital [2]. In sum, Bourdieu understands practice as the result of social structures on a particular field where certain rules apply, and Bourdieu's theoretical vision embraces understanding at the level of person and of wider society. 
Implications of Bourdieu's Theory. The evidence is overwhelming that one has to appreciate the power of Bourdieu's insights into how an entire social formation works. The truth is that Bourdieu's works have been translated into two dozen languages and several works of his are considered classics, not only in sociology, but also in anthropology, education, and cultural studies. Specifically, Bourdieu's best known book Distinction: A Social Critique of the Judgment of Taste, was judged the sixth most important sociological work of the twentieth century by the International Sociological Association [3]. Bourdieu's theory is used as theoretical framework and applied to different circumstances and areas of research, for instance organizational studies, marketing, or human resource management, etc. Particularly, Bourdieu's theory of cultural reproduction has been highly influential within the sociology of education [4]. Bourdieu routinely sought to connect his theoretical ideas with empirical research and his work can be seen as sociology of culture or, as he described it, a "Theory of Practice"[3]. It's believed that Bourdieu's theory is substantive enough to be potentially useful to empirical researchers although it does not constitute a cohesive theory within itself. In brief, Bourdieu represents a flexible theoretical approach with many elements considered together and researchers in various fields have often made reference to Bourdieu's diverse thoughts.

Criticism on Bourdieu's Theory. Bourdieu's theory has been subjected to genuine critical examination by various researchers. The criticism can be denoted in various ways. Firstly, the notion of habitus is central to Bourdieu's thought, yet it is never clearly defined. Given the vagueness of this, it is not surprising that the concept of habitus is condemned as "ambiguous and overloaded" [5]. Besides habitus, other concepts in Bourdieu's theory are not constructed clearly by Bourdieu. It's argued that Bourdieu's project is extremely ambitious as many elements of his work are theoretically incoherent and have no clear use for empirical researchers. What's more, Bourdieu's contribution of "structuralize constructivism or constructivist structuralism" (i.e. the reconciliation between structure and agency or macro and micro) is also criticized for not being sound enough [6]. Bourdieu thinks that the notion of habitus solves the conflict between structure and determinism on the one hand and agency and individualism on the other, however, some hold that the statement is quite unjustified as it has no place not only for individual agency, but even for individual consciousness[7]. Apart from above, more criticisms could be found in a large body of literature on Bourdieu' theory. In sum, criticisms of Bourdieu's thought have been made on many grounds and from various viewpoints as scholars and researchers are more interested in working on it.

\section{The Insights into Liaoning Scientific Foreign Language Talents with View to Bourdieu' Theory}

For Habitus to React to the World. Although educational aspirations expressed are inadequate for attaining one's desired achievement, the habitus of Liaoning scientific foreign language talents in educational field is associated with higher educational attainment and may contribute to the improvement and development of Liaoning scientific foreign language agents. The habitus assures the collective belief in the rules of the social game and that agents act in accordance with their position on the field, which depends on their relative amount and structure of economic, cultural (and social) capital, as all agents tacitly recognize "the value of the stakes of the game and the practical mastery of its rules" [8]. The habitus is in some way formed by the objective chances of success shared by the class. The habitus in turn determines the actions of the members of the class. It's argued that success in the education system is facilitated by the possession of cultural capital and of higher class habitus, and lower-class pupils do not in general possess these traits, so the failure of the majority of these pupils is inevitable. In brief, given the role of habitus in higher education in determining scientific foreign language outcomes, it is critical for Liaoning scientific foreign language talents to possess habitus, especially for those from disadvantaged backgrounds.

For More Capitals to Make a Change. In order to enter and move on social fields, Liaoning scientific foreign language talents need to mobilize and utilize all sorts of capitals. For Bourdieu, battles between agents are principally about relative positions within the field, i.e. maximizing capital, wherefore individual strategies in conformity with the rules of the game are of necessity [9]. Agents 
are competitors for positions within the field as they pursue the same objective in the game. Bourdieu distinguishes between four types of capital, namely economic, cultural, social and symbolic capital [10], and social capital is most associated with educational attainment. Bourdieu's emphasis on the non-material resources possessed by the higher-class household is to be welcomed. This suggests that the dramatic fall in the material costs to families of education have not diminished the degree of association between class origins and educational attainment and the educational advantage which higher-class parents pass on to their children may not be entirely caused by economic factors, and that the notion of cultural capital is therefore worthy of serious attention [4]. All in all, resources should be at the disposal of Liaoning scientific foreign language talents so that these resources are converted into educational credentials and for a better position to enter and move on social fields.

\section{Development of Liaoning Scientific Foreign Language Talents with View to Bourdieu' Theory}

The Update of Learning Habitus in Learning. The people best able to regulate their learning outcomes are the ones who can obtain an updated learning habitus in learning field. Liaoning scientific foreign language talents are encouraged to possess a set of habitus in coping with language difficulties. The habitus consists of both the tendency to hold and use one's body in a certain ways, such as posture and accent and more abstract mental habits, schemes of perception, classification, appreciation, feeling, and action [11]. Few experiences will make people develop habitus and grow as a person more than developing the abilities of learning autonomously. Learner autonomy is enabled by Liaoning scientific foreign language talents through taking charge of their learning (i.e. making informed decision and make proactive action plan). Besides, other learning elements should be involved in the process of developing better habitus in learning field. As Bourdieu suggested, the habitus is not only structured by an individuals' objective past position in the social structure, but is also collective and socially shaped [11]. The habitus is durable but evolving and is continually adjusted to the current context and reinforced by further experience. In sum, individual and collective efforts should be made by Liaoning scientific foreign language talents to cultivate learning habitus so as to deal with new solutions to new situations in scientific foreign language learning.

The Consideration of Social Context into Learning. The benefits of considering social context in the process of foreign language learning are fairly clear and far more than what are mentioned. Firstly, we cannot learn the target language well if we do not know the patterns and norms of the target culture. It has been widely accepted that language and culture are inextricably linked to one another. Without either of them, they cannot be acquired by people. Acquisition of culture is as important as language learning itself, and an effective language learner must be an effective culture acquirer as well. What's more, foreign language learning requires meaningful interaction in the natural communicative contexts. Engagement into social communication of a foreign language is to make up for the lack of authentic foreign language situation in classroom. As foreign language is usually learned in environments where the language they learn is not the language of the community and the school, more works should be done by foreign language instructors. It's suggested that Liaoning scientific foreign language talents should actively seek for chances of utilizing foreign language and be expected to possess the ability to communicate on a wider, quicker and clearer basis. These expertise and experience can boost self-confidence of foreign language learners. To sum up, Liaoning scientific foreign language talents should find natural way of picking up a language by using it in natural, communicative situations, as foreign language learners are concerned not with the form of their utterances but with the messages they are conveying and understanding.

The Interaction with Elements in Economic Field. No success can be made in cultivating foreign language talents without taking sufficient consideration of elements in economic field. In other words, the development of Liaoning scientific foreign language talents should take economic development into account. The evidence is overwhelming that language is linked to local economic development, and its one important ingredient influencing the local economic growth. Just as what Coulmas put in his paper, economic developments influence the emergence, expansion, or decline of 
languages [12]. Various economic factors have an impact on changes in the meaning of languages as language education is economically driven. When we look at language in its global role, the economic dimension is what determines its value and status in countries with aspirations to participate in the knowledge economy. And it's especially true to scientific foreign language talents as they are anticipated to have a better performance in scientific foreign language in occupational field. In the regard, potential job opportunities should be researched and analyzed through need analysis by researchers and instructors. With view to the big data out of need analysis, foreign language instructors can be in a better position to make out educational policies and take pedagogical approaches. In brief, the interaction between economy and language is a reality, and doors open as the interaction with elements in economic field is on rise in the process of cultivating Liaoning scientific foreign language talents.

The Access to All Sorts of Learning Capitals. Although habitus ensures that agents act in accordance with the field specific rules, no successful learning can take place without getting access to sufficient learning capitals. Agents need to be endowed with a specific quantity and structure of resources they can put at stake in order to obtain the right to enter a social field [13]. Firstly, those who mostly hold economic capital find more opportunities in foreign language learning, for instance going abroad for authentic learning situation. As not everyone can get economic inheritance (e.g., accent or property), educational institution should cut learning fees and offer assistance programs for those who have difficulties paying tuitions. Secondly, cultural capital can be more likely to be possessed by learners if learners seek for correct learning methods and sufficient learning resources, and would like work on it with perseverance and creativity. Initiative should be made by learners to achieve educational attainment so that they can benefit from holding more cultural capital. Thirdly, learners should be engaged into the actual or potential resources which are linked to possession of a durable network of more or less institutionalized relationships. In this regard, instructors are encouraged to involve learners in teamwork and enhance their membership in group. Lastly, learners have much to do with power through taking charge of foreign language learning and being critical about learning elements. To sum up, various approaches can be attempted by Liaoning scientific foreign language learners as four types of capital have implications in developing scientific foreign language talents.

\section{Conclusions}

In attempting to develop critical research on the development of Liaoning scientific foreign language talents we ask how the social theory of Pierre Bourdieu assists this research. It's found that the insights into Liaoning scientific foreign language talents with view to Bourdieu' theory is profound and influential. Efforts should be made for foreign language learners to go for habitus to react to the world and for more capitals to make a change whist cultivating Liaoning scientific foreign language talents. It's suggested that pedagogical strategies on scientific foreign language be implemented through engaging learners in the process of updating learning habitus in learning, considering social context into learning, interacting with elements in economic field and getting access to all sorts of learning capitals, so as to ultimately develop linguistic competence among scientific foreign language talents.

\section{Acknowledgements}

This work is part of the project of On Cultivating and Developing Liaoning Scientific Foreign Language Talents with View to Bourdieu' Theory. This research was supported by the fund of Liaoning Planning of Philosophy and Social Science (Project No. L16CYY001).

\section{References}

[1] J. Gaventa, Power after Lukes: a review of the literature, Brighton: Institute of Development Studies, 2003. 
[2] M. Walther, Reparation to France and Germany A Comparative Study Based on Bourdieu's Theory of Practice, Springer Gabler, Wiesbaden, 2014.

[3] Information on https://en.wikipedia.org/wiki/Pierre_Bourdieu Sullivan.

[4] Bourdieu and Education: How useful is Bordieu's theory for researchers? The Netherlands' Journal of Social Sciences, 38 (2002).

[5] R. Nash, Bourdieu on education and social and cultural production, British Journal of Sociology of Education, 11 (1990).

[6] P. Bourdieu, Language and Symbolic Power, Polity Press, Cambridge, 1989.

[7] King, Thinking with Bourdieu Against Bourdieu: A 'Practical' Critique of the Habitus, Sociological Theory, 18 (2000).

[8] P. Bourdieu, L. J. D. Wacquant, An Invitation to Reflexive Sociology, The University of Chicago Press, 1992.

[9] Iellatchitch, M. Mayrhofer \& M. Meyer, Career field: a small step towards a grand career theory? International Journal of Human Resource Management, 23 (2003).

[10] P. Bourdieu, The forms of capital. In J. Richardson (Ed.) Handbook of Theory and Research for the Sociology of Education (New York, Greenwood), 1986.

[11]P. Bourdieu, Distinction: A Social Critique of the Judgement of Taste, Harvard University Press, 1987.

[12]F. Coulmas, Language and economy, Oxford: Blackwell Publishers, 1992.

[13] Accardo, Introduction à une sociologie critique,Lire Pierre Bourdieu, Éditions Agone, coll, Eléments , (382) 2006. 